\title{
DINÂMICA DE ÍONS EM SOLO ÁCIDO LIXIVIADO COM EXTRATOS DE RESÍDUOS DE ADUBOS VERDES E SOLUÇÕES PURAS DE ÁCIDOS ORGÂNICOS ${ }^{1}$
}

\author{
JÚLIO CEZAR FRANCHINI ${ }^{2}$, MARIO MIYAZAWA ${ }^{3}$, MARCOS ANTONIO PAVAN ${ }^{4}$ e EURIPEDES MALAVOLTA ${ }^{5}$
}

\begin{abstract}
RESUMO - A influência da aplicação de resíduos vegetais na dinâmica de íons em solos ácidos é pouco conhecida. Neste estudo, a mobilidade de íons em amostra do horizonte Bw de um Latossolo VermelhoEscuro álico lixiviado com soluções puras de ácidos cítrico e succínico e extratos aquosos de resíduos de nabo forrageiro (Raphanus sativus) e aveia-preta (Avena strigosa) foi avaliada em colunas de solo $(5,10$, 20 e $40 \mathrm{~cm}$ de altura por $4 \mathrm{~cm}$ de diâmetro). Após a percolação das soluções e extratos pelas colunas de solo determinaram-se, nas soluções efluentes, os teores de $\mathrm{Ca}\left(\mathrm{Ca}_{\mathrm{s}}\right), \mathrm{Mg}\left(\mathrm{Mg}_{\mathrm{s}}\right), \mathrm{K}\left(\mathrm{K}_{\mathrm{s}}\right), \mathrm{Al}$ total $\left(\mathrm{Al}_{\mathrm{st}}\right)$, orgânico $\left(\mathrm{Al}_{\mathrm{so}}\right)$, monomérico $\left(\mathrm{Al}_{\mathrm{sm}}\right)$ e carbono orgânico dissolvido. No solo, foram determinados os teores trocáveis de $\mathrm{Ca}\left(\mathrm{Ca}_{\mathrm{tr}}\right), \mathrm{Mg}\left(\mathrm{Mg}_{\mathrm{tr}}\right), \mathrm{K}\left(\mathrm{K}_{\mathrm{tr}}\right)$ e $\mathrm{Al}\left(\mathrm{Al}_{\mathrm{tr}}\right)$ e o $\mathrm{pH}\left(\mathrm{CaCl}_{2}\right)$. Os ácidos cítrico e succínico aumentaram os teores de $\mathrm{Al}_{\mathrm{st}} \mathrm{e} \mathrm{Ca}$, respectivamente, causando reduções nas frações trocáveis desses elementos no solo. O extrato de aveia-preta foi mais efetivo na remoção do $\mathrm{Ca}_{\mathrm{tr}}$ e o de nabo forrageiro na do $\mathrm{Al}_{\text {tr }}$. O decréscimo de $\mathrm{Ca}_{\mathrm{tr}}$ e $\mathrm{Al}_{\mathrm{tr}}$ foi seguido do aumento do $\mathrm{K}_{\mathrm{tr}}$. A formação de complexos entre $\mathrm{Ca}_{\mathrm{s}} \mathrm{e}$ $\mathrm{Al}_{\mathrm{tr}}$ com compostos orgânicos de baixo peso molecular foi sugerida como o provável mecanismo responsável pela mobilidade dos íons polivalentes no subsolo de solos ácidos após a aplicação dos extratos de resíduos vegetais e das soluções puras de ácidos orgânicos.
\end{abstract}

Termos para indexação: complexos orgânicos, mobilidade de cátions, cálcio, alumínio.

\section{DYNAMIC OF IONS IN ACID SOIL LEACHED WITH GREEN MANURE RESIDUES EXTRACTS AND PURE SOLUTIONS OF ORGANIC ACIDS}

\begin{abstract}
The influence of green manure residues addition in the dynamic of ions in acid soils is not well known. In this study, ion mobility in a sample of the Bw horizon of an Dark-Red Latosol (Oxisol), leached with citric and succinic acid pure solutions and with aqueous residue extracts of black oats (Avena strigosa) and oil seed radish (Raphanus sativus) were evaluated in soil columns $(5,10,20$, and $40 \mathrm{~cm}$ long by $4 \mathrm{~cm}$ diameter). After the solutions and extracts passed through the soil columns, the following parameters were determined: solubles contents of $\mathrm{Ca}_{\mathrm{s}}, \mathrm{Mg}_{\mathrm{s}}, \mathrm{K}_{\mathrm{s}}, \mathrm{Al}_{\mathrm{st}}$ (total), $\mathrm{Al}_{\mathrm{so}}$ (organic), $\mathrm{Al}_{\mathrm{sm}}$ (monomeric) and dissolved organic carbon. In soil, the parameters evaluated were the exchangeable contents of $\mathrm{Ca}_{\mathrm{ex}}, \mathrm{Mg}_{\mathrm{ex}}, \mathrm{K}_{\mathrm{ex}}$, and $\mathrm{Al}_{\mathrm{ex}}$ and $\mathrm{pH}\left(\mathrm{CaCl}_{2}\right)$. Citric and succinic acids increased $\mathrm{Al}_{\mathrm{st}}$ and $\mathrm{Ca}_{\mathrm{s}}$ contents, respectively, resulting in decreasing exchangeable fractions of these elements in soil. Black oats extract was more effective to extract $\mathrm{Ca}_{\mathrm{ex}}$ and oil seed radish to extract $\mathrm{Al}_{\mathrm{ex}}$. The decrease in $\mathrm{Ca}_{\mathrm{ex}}$ and $\mathrm{Al}_{\mathrm{ex}}$ was followed by an increase in $\mathrm{K}_{\mathrm{ex}}$. Organic complexes formed with low molecular organic ligands and $\mathrm{Ca}_{\mathrm{s}}$ and $\mathrm{Al}_{\mathrm{ex}}$ were suggested to play a role in the mobility of ions in subsoils of acid soils after the addition of both crop residues extracts and pure organic acid solutions.
\end{abstract}

Index terms: organic complexes, cation mobility, calcium, aluminum.

${ }^{1}$ Aceito para publicação em 11 de março de 1999.

Extraído da tese de Doutorado, apresentada pelo primeiro autor à Universidade de São Paulo, Piracicaba, SP. Apoio da FAPESP, processos 94/2209-1 e 94/0669-5.

${ }^{2}$ Eng. Agr., Dr., Rua Pará 1119, ap. 504, CEP 86010-450

Londrina, PR. E-mail: hungria@sercomtel.com.br

${ }^{3}$ Químico, Dr., Instituto Agronômico do Paraná (IAPAR), Caixa Postal 481, CEP 86047-902 Londrina, PR. Bolsista do CNPq. E-mail: miyazawa@pr.gov.br

${ }^{4}$ Eng. Agr., Ph.D., IAPAR. Bolsista do CNPq.

${ }^{5}$ Eng. Agr., Prof. Catedrático, Seção de Nutrição Mineral de Plantas, CENA/USP, Caixa Postal 96, CEP 13416-000 Piracicaba, SP.

\section{INTRODUÇÃO}

Efeitos benéficos do manejo orgânico de solos ácidos têm sido observados em diversos sistemas agrícolas, cujas principais alterações químicas na camada de 0 a $20 \mathrm{~cm}$ de profundidade são: elevações do $\mathrm{pH}$ e do teor de $\mathrm{Ca}$ em detrimento do $\mathrm{Al}$ (Sanchez et al., 1982; Hue \& Amien, 1989; Bessho \& Bell, 1992). Em alguns casos, esses efeitos se estendem à subsuperfície do solo (Watt et al., 1991; 
Pavan, 1994; Liu \& Hue, 1996; Oliveira \& Pavan, 1996). Em geral, os autores atribuem à formação de fulvatos de $\mathrm{Ca}$, resultantes de um estádio avançado de decomposição do material orgânico, como responsáveis pela mobilização do $\mathrm{Ca}$, devido à alta estabilidade do complexo orgânico. Contudo, compostos orgânicos de baixo peso molecular são as formas predominantes no período inicial de decomposição de resíduos vegetais e sua reação no solo é caracterizada pela rapidez e curta duração, concentrando-se nas duas primeiras semanas após a aplicação dos resíduos (Miyazawa et al., 1993; Aoyama, 1996a, 1996b; Leal et al., 1996). A drástica redução do teor total de $\mathrm{C}$ dissolvido e da fração de menor peso molecular em favorecimento da fração de maior peso molecular (ácidos húmicos e fúlvicos) durante esse período pode ser a causa de tal comportamento (Aoyama, 1996a, 1996b).

A capacidade de compostos orgânicos de baixo peso molecular para solubilizar, mobilizar e reduzir a toxidez de Al é bem estabelecida (Wright et al., 1985; Hue et al., 1986; Pohlman \& McColl, 1986; Hue $\&$ Amien, 1989). No entanto, a possibilidade de esses compostos mobilizarem o $\mathrm{Ca}$ tem recebido pouca atenção.

Nesse contexto, o presente estudo comparou as alterações na composição química da solução e do complexo de troca de uma amostra de subsolo ácido após a aplicação de compostos orgânicos hidrossolúveis extraídos de resíduos vegetais de adubos verdes e de soluções puras de ácidos orgânicos.

\section{MATERIAL E MÉTODOS}

Amostra do horizonte Bw de um Latossolo VermelhoEscuro álico (LEa), coletada em área não cultivada, foi secada ao ar, moída, e passada em peneira de $2 \mathrm{~mm}$. Sua composição química e granulométrica encontra-se na Tabela 1. Amostras de nabo forrageiro (Raphanus sativus) e aveia-preta (Avena strigosa) foram coletadas no estádio de pleno florescimento em áreas experimentais do Instituto Agronômico do Paraná (IAPAR) em Londrina, secadas em estufa a $65^{\circ} \mathrm{C}$ durante 48 horas, moídas, passadas em peneira de $1 \mathrm{~mm}$, e armazenadas em caixas de papelão. A composição química dos materiais vegetais é apresentada na Tabela 2. Foram preparadas colunas de PVC com diâmetro interno de $4 \mathrm{~cm}$, por $5,10,20$ e $40 \mathrm{~cm}$ de altura (Fig. 1) e adicionaram-se, respectivamente, 75, 150, $300 \mathrm{e}$ $600 \mathrm{~g}$ de solo, obtendo-se uma densidade aparente de $1,19 \mathrm{~kg} \mathrm{dm}^{-3}$. A parte inferior da coluna foi colocada sobre um funil de plástico contendo uma fina camada de espuma sintética. O funil foi fixado à coluna com uma fita adesiva. Esse sistema foi adotado para facilitar a drenagem e evitar perdas de solo. A capacidade de retenção de água do solo contido na coluna de $40 \mathrm{~cm}$ de altura correspondeu a $23 \%$ da massa de solo, o equivalente a $140 \mathrm{~mL}$ de água ou uma precipitação de $110 \mathrm{~mm}$. Após o empacotamento, em cada conjunto de colunas foram aplicados os seguintes tratamentos: controle (sem adição de resíduos vegetais e de ácidos orgânicos); resíduo de aveia-preta; resíduo de nabo forrageiro; soluções puras de ácido cítrico na forma de citrato de Ca e de $\mathrm{K}$; soluções puras de ácido succínico na forma de succinato de $\mathrm{Ca}$ e de $\mathrm{K}$.

No caso dos adubos verdes, adicionaram-se $6 \mathrm{~g} \mathrm{coluna}^{-1}$ de cada resíduo vegetal, equivalente a $20 \mathrm{Mg} \mathrm{ha}^{-1}$ de matéria seca. Os resíduos vegetais foram dispostos sobre papel de filtro adaptado na parte superi-

TABELA 1. Carbono orgânico (C org.), pH, acidez total (H+Al), cátions trocáveis e granulometria do solo ${ }^{1}$.

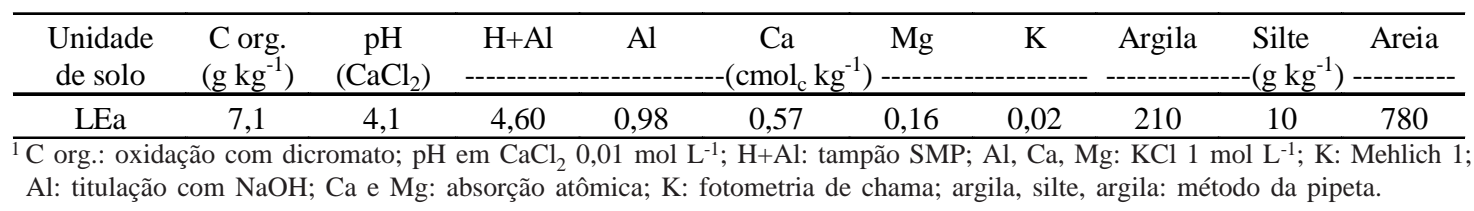

TABELA 2. Teores totais $\left(\mathrm{g} \mathrm{kg}^{-1}\right)$ de nitrogênio $(\mathrm{N})$, fósforo $(\mathrm{P})$, potássio $(\mathrm{K})$, cálcio $(\mathrm{Ca})$ e magnésio $(\mathrm{Mg})$ nos resíduos vegetais ${ }^{1}$.

\begin{tabular}{lccccc}
\hline Resíduo & $\mathrm{N}$ & $\mathrm{P}$ & $\mathrm{K}$ & $\mathrm{Ca}$ & $\mathrm{Mg}$ \\
\hline Nabo forrageiro & 29,4 & 3,2 & 29,9 & 19,2 & 3,8 \\
Aveia-preta & 18,4 & 2,1 & 41,7 & 2,9 & 1,6 \\
\hline
\end{tabular}

${ }^{1} \mathrm{~N}$ : Kjeldahl; P, K, Ca e Mg: extrato $\mathrm{HCl} 1$ mol L-1; P, Ca e Mg: emissão atômica induzida por plasma; K: fotometria de chama. 
or da coluna (Fig. 1). Prepararam-se soluções puras de ácidos cítrico e succínico na concentração de $5 \mathrm{mmol} \mathrm{L}^{-1}$ com os íons Ca e K (Tabela 3). As soluções contendo Ca foram preparadas a partir da dissolução dos ácidos orgânicos puros em água, adição de $\mathrm{Ca}(\mathrm{OH})_{2}$ para obter uma concentração aproximada de $4 \mathrm{mmol} \mathrm{L}^{-1}$ de Ca e ajuste do pH para 5,0 com solução de $\mathrm{KOH} 0,1 \mathrm{~mol} \mathrm{~L}^{-1}$. O ajuste do $\mathrm{pH}$ somente foi necessário para a solução de citrato de $\mathrm{Ca}$, razão pela qual tal solução também contém K. Nas soluções puras na forma de sais de $\mathrm{K}$ a concentração do cátion foi estabelecida pela quantidade de íon $\mathrm{OH}$ necessário para ajuste do $\mathrm{pH}$. Utilizou-se o $\mathrm{pH}$ 5,0 para as soluções puras de ácidos orgânicos, visando manter o nível de acidez próximo ao observado nos extratos em água dos resíduos vegetais.

Antes do ínicio dos tratamentos analisaram-se os compostos hidrossolúveis presentes nos resíduos

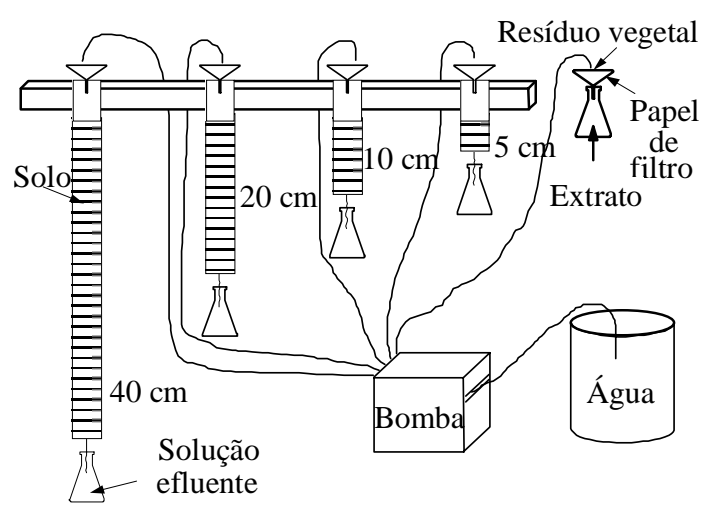

FIG. 1. Conjunto de colunas utilizado para o tratamento com resíduos vegetais. No caso das soluções puras de ácidos orgânicos o reservatório de água foi substituído pela respectiva solução. vegetais através do seguinte procedimento de extração: transferiram-se $6 \mathrm{~g}$ de resíduo vegetal para um funil contendo papel de filtro; aplicaram-se $140 \mathrm{~mL}$ de água destilada (equivalente a uma precipitação de $110 \mathrm{~mm}$ na coluna de $40 \mathrm{~cm}$ ) utilizando uma bomba peristáltica a uma taxa de $0,5 \mathrm{~mL} \mathrm{~min}{ }^{-1}$; coletou-se a solução em erlenmeyer e analisaram-se o pH; a acidez devida aos ácidos orgânicos protonados $(\mathrm{RCOOH})$ pela titulação com $\mathrm{NaOH}$ utilizando azul de bromotimol como indicador; $\mathrm{Ca}$ e Mg por espectrometria de emissão atômica induzida por plasma; K por fotometria de chama e carbono orgânico dissolvido (COD) utilizando um analisador de carbono total. Estudos preliminares demonstraram que esse volume de água foi suficiente para extração completa dos elementos hidrossolúveis contidos nos resíduos de aveiapreta e nabo forrageiro.

Após a transferência dos resíduos vegetais para a parte superior das colunas, estabeleceu-se um programa de irrigação no qual foram adicionados $140 \mathrm{~mL}$ de água destilada com auxílio de uma bomba peristáltica a uma taxa $0,5 \mathrm{~mL} \mathrm{~min}^{-1}$. Para as soluções puras foram adicionados $140 \mathrm{~mL}$ das soluções em cada coluna, utilizando o mesmo procedimento descrito para os resíduos vegetais. A seguir, retirou-se o papel de filtro contendo os resíduos e adicionou-se mais $140 \mathrm{~mL}$ de água destilada em todas as colunas, totalizando $280 \mathrm{~mL}$ de água, equivalente a uma precipitação de $220 \mathrm{~mm}$.

Nas soluções efluentes das colunas de solo determinaram-se a acidez total $(\mathrm{H}+\mathrm{Al})$ por titulação com $\mathrm{NaOH}$; acidez devida aos ácidos orgânicos protonados (RCOOH), por titulação com $\mathrm{NaOH}$ após adição de flúor em excesso na solução para eliminar a acidez devida ao $\mathrm{Al}$ (em ambos os casos utilizou-se azul de bromotimol como indicador); $\mathrm{Ca}, \mathrm{Mg}$ e Al solúveis por espectrometria de emissão atômica induzida por plasma; K solúvel por fotometria de chama; COD com analisador de carbono total e formas orgânicas e inorgânicas de $\mathrm{Al}$ pela técnica de separação com resina de troca catiônica. A técnica de separação das

TABELA 3. Composição química das soluções puras e dos extratos de resíduos vegetais ${ }^{1}$.

\begin{tabular}{|c|c|c|c|c|c|c|c|}
\hline Solução & $\mathrm{pH}$ & $\mathrm{RCOOH}$ & $\mathrm{Mg}$ & $\mathrm{Ca}$ & $\mathrm{K}$ & Total & $\operatorname{COD}\left(\mathrm{mg} \mathrm{L}^{-1}\right)$ \\
\hline Citrato $\mathrm{Ca}$ & 50 & 25 & & 42 & 25 & 92 & 337 \\
\hline Citrato K & 5,0 & 5,1 & & & 5,1 & 10,2 & 357 \\
\hline Succinato $\mathrm{Ca}$ & 5,0 & 3,8 & & 4,4 & & 8,2 & 247 \\
\hline Succinato K & 5,0 & 3,4 & & & 3,5 & 6,9 & 240 \\
\hline Aveia-preta & 6,9 & 0,0 & 1,2 & 0,6 & 22,8 & 24,6 & 1.564 \\
\hline Nabo forrageiro & 5,7 & 2,9 & 4,5 & 9,1 & 14,7 & 31,2 & 1.223 \\
\hline
\end{tabular}

${ }^{1} \mathrm{RCOOH}$ : ácidos orgânicos protonados; Total: $\mathrm{RCOOH}+\mathrm{Mg}+\mathrm{Ca}+\mathrm{K}$; COD: carbono orgânico dissolvido. 
formas de $\mathrm{Al}$ consistiu do seguinte procedimento: transferiu-se $2 \mathrm{~cm}^{3}$ de resina pré-condicionada (CHELEX 100, convertida à forma de $\mathrm{H}$, com $\mathrm{HNO}_{3}$ e ajustada a $\mathrm{pH} 4,5$ com $\mathrm{NaOH}$ ) para seringas de $20 \mathrm{~cm}^{3}$, passou-se pela resina uma alíquota de $10 \mathrm{~mL}$ da solução efluente e a seguir $10 \mathrm{~mL}$ de água destilada. Considerou-se que o Al que passou pela resina estava na forma orgânica $\left(\mathrm{Al}_{\mathrm{o}}\right)$ e o retido como espécie monomérica $\left(\mathrm{Al}_{\mathrm{m}}\right)$. Para detalhes dessa técnica, consultar Campbell et al. (1983) e Driscoll (1984).

Após a completa drenagem das soluções, em cada tratamento, desmontaram-se as colunas de $40 \mathrm{~cm}$, separando-se o solo em camadas de 0 a 5,5 a 10, 10 a 20 e 20 a $40 \mathrm{~cm}$. Determinaram-se o pH em solução de $\mathrm{CaCl}_{2}$ $0,01 \mathrm{~mol} \mathrm{~L}^{-1}$ na relação 1:2,5 (solo:solução); $\mathrm{Ca}, \mathrm{Mg}$ e Al extraídos com solução de $\mathrm{KCl} 1 \mathrm{~mol} \mathrm{~L}^{-1}$ na relação 1:10 (solo:solução), sendo $\mathrm{Ca}$ e $\mathrm{Mg}$ determinados por espectrofotometria de absorção atômica e Al por titulação com $\mathrm{NaOH}$ 0,015 $\mathrm{N}$ com o indicador azul de bromotimole K extraído com solução de Mehlich ( $\mathrm{HCl} \mathrm{0,05} \mathrm{M}+\mathrm{H}_{2} \mathrm{SO}_{4}$ 0,0125 M) e determinado por fotometria de chama.

Para permitir a comparação relativa dos efeitos das soluções puras de ácidos orgânicos e dos extratos de resíduos vegetais sobre a química do solo e da solução, a concentração de cátions presentes nas mesmas foi transformada em valores percentuais sendo considerado como $100 \%$ o somatório de K, Ca, Mg e H (como RCOOH) em cada solução ou extrato (Tabela 3). A composição percentual de cátions das soluções efluentes das colunas de solo após percolação das soluções puras e dos extratos vegetais foi calculada com base no total de cátions na solução original. Foram considerados como cátions extraídos do solo todos aqueles que estavam ausentes na solução inicial e presentes na solução efluente de determinada camada de solo ou, estando presentes na solução inicial, tiveram sua concentração aumentada após o mesmo procedimento. Quando o inverso foi observado, os cátions foram considerados como retidos pelo solo. A retenção foi considerada apenas como redução do teor em solução, sem distinguir reações de precipitação, adsorção, etc., ou, cátions simplesmente mantidos na água armazenada no espaço poroso do solo.

\section{RESULTADOS E DISCUSSÃO}

Os extratos dos resíduos vegetais apresentaram composições químicas distintas. No extrato de aveiapreta, o K foi o cátion predominante, enquanto no de nabo forrageiro, embora o K continuasse a ser o cátion principal, $\mathrm{Ca}$ e $\mathrm{Mg}$ estavam presentes em maiores proporções (Tabela 3). A concentração de COD foi elevada em ambos os resíduos vegetais, sendo maior na aveia-preta. O COD nas soluções puras, equivalente à concentração de $5 \mathrm{mmol} \mathrm{L}^{-1}$ do ácido orgânico, representou de 15 a 30\% do observado nas soluções de resíduos vegetais (Tabela 3 ).

A titulação das soluções com $\mathrm{NaOH}$ antes da aplicação no solo estima o teor de ácido orgânico protonado ( $\mathrm{RCOOH}$ ) (Tabela 3). A fração de ácido cítrico protonado foi reduzida proporcionalmente à quantidade de cátions nas soluções de citrato de $\mathrm{Ca}$ e de citrato de K. No caso das soluções com ácido succínico, a forma protonada foi semelhante nas soluções contendo Ca ou K. O extrato de aveia-preta não apresentou grupos orgânicos na forma protonada devido ao $\mathrm{pH}$ elevado, enquanto o de nabo forrageiro apresentou 2,9 $\mathrm{mmol}_{\mathrm{c}} \mathrm{L}^{-1}$ (Tabela 3 ).

Nas Figs. 2 e 3 são apresentadas as alterações na composição química das soluções puras e extratos vegetais após a percolação pelas diferentes camadas de solo. Nas soluções puras, a retenção, pelo solo, dos cátions adicionados, foi relacionada, em alguns casos, com o ânion acompanhante. Os cátions $\mathrm{H}$ e Ca foram retidos pelo solo em maior proporção quando acompanhados do ânion citrato em relação ao succinato (Figs. 2 e 3). Para o extrato de nabo forrageiro, o Ca foi retido até $10 \mathrm{~cm}$ de profundidade, sendo, então, substituído pelo K nas camadas posteriores (Fig. 2). O K apresentou indiferença ao tipo de ânion, sendo, preferencialmente, retido pelo solo (Figs. 2 e 3). Este comportamento foi marcante no extrato de aveia-preta (Fig. 3).

O Al foi o principal cátion extraído do solo na maioria das soluções avaliadas (Figs. 2 e 3), exceto para a solução de succinato de $\mathrm{K}$ e para o extrato de aveiapreta, onde a extração de Ca predominou no sistema (Fig. 3). A maior extração de $\mathrm{Al}$ pelo ânion citrato em relação ao succinato (Figs. 2 e 3 ) está de acordo com a constante de estabilidade dos complexos formados com Al por esses ácidos orgânicos (Tabela 4). Tal fato pode ser comprovado pelo $\mathrm{Al}_{\mathrm{o}}$ determinado em ambas as soluções (Tabela 5). Nas soluções com citrato, acima de $90 \%$ do Al estava na forma orgânica, enquanto nas soluções com succinato o Al estava, predominantemente, na forma monomérica. No caso do succinato, deve ser observado que tanto o $\mathrm{Ca}$ quanto o $\mathrm{K}$ presentes nas soluções não poderiam responder pela extração de $\mathrm{Al}$, sugerindo 
Cátions totais (\%)
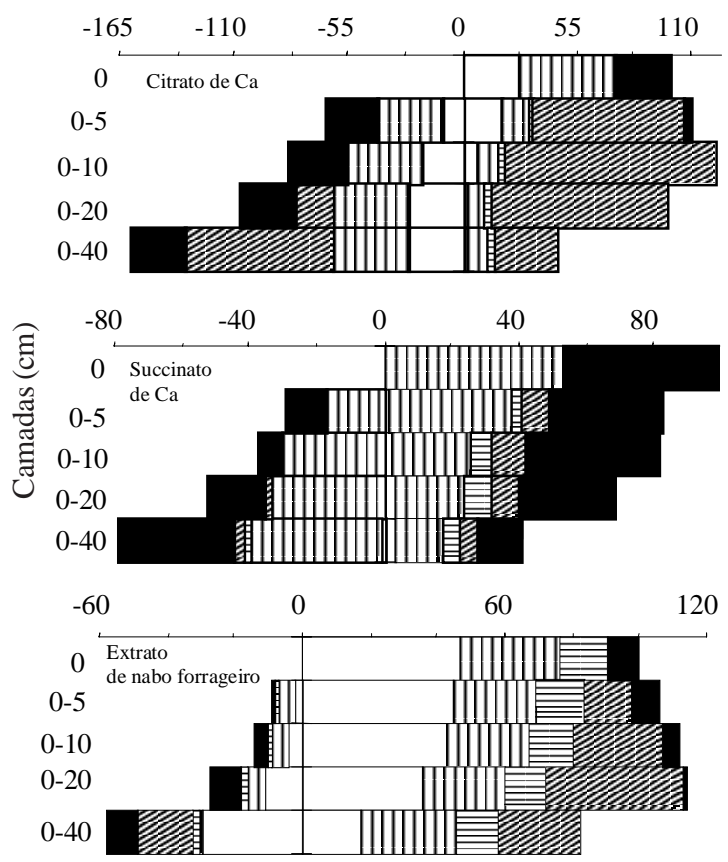

FIG. 2. Composição relativa de cátions sóluveis (valores positivos) e cátions retidos pelo solo (valores negativos) após percolação das soluções de citrato de $\mathrm{Ca}$, succinato de $\mathrm{Ca}$ e do extrato de nabo forrageiro por camadas de solo com diferentes profundidades $(0-5,0-10$, 0-20, 0-40 cm). A camada zero corresponde à composição relativa de cátions das soluções puras e do extrato de resíduo vegetal antes de serem percoladas através das camadas de solo. Os valores percentuais foram calculados com base na concentração de cátions apresentada na Tabela 3. Cátions: K $\square$; Ca $\mathbf{m}$; $\mathrm{Mg}$ 冒; $\mathrm{Al} \mathbb{Z}$; RCOOH $\square$. Valores descontados do controle em água.

que o Al foi extraído pela complexação com succinato e que tal complexo não teria estabilidade suficiente para competir pelo Al com a resina durante o fracionamento. A extração de Al foi observada, principalmente, nas camadas de 5 e $10 \mathrm{~cm}$. Nas camadas posteriores, o Al em solução foi mais retido pelo solo (Figs. 2 e 3). O Al extraído do solo pelo extrato de nabo forrageiro foi su-
Cátions totais $(\%)$
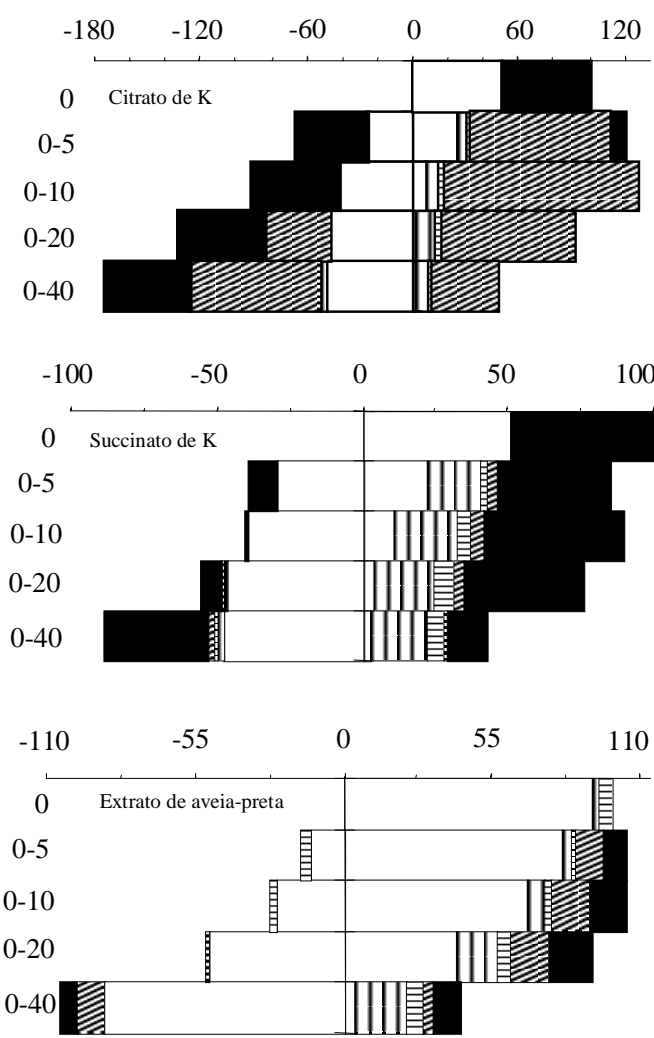

FIG.3. Composição relativa de cátions sóluveis (valores positivos) e cátions retidos pelo solo (valores negativos) após percolação das soluções de citrato de $K$, succinato de $K$ e do extrato de aveia-preta por camadas de solo com diferentes profundidades $(0-5,0-10$, $0-20,0-40 \mathrm{~cm})$. A camada zero corresponde à composição relativa de cátions das soluções puras e do extrato de resíduo vegetal antes de serem percoladas através das camadas de solo. Os valores percentuais foram calculados com base na concentração de cátions apresentada na Tabela 3. Cátions: K $\square$; Ca $\mathbf{m}$; $\mathrm{Mg}$ 策; $\mathrm{Al}$; RCOOH $\square$ Valores descontados do controle em água.

perior ao extraído pelo de aveia-preta e similar ao extraído pelas soluções com citrato. Os complexos formados no extrato de nabo forrageiro têm estabilidade elevada, devido ao predomínio de $\mathrm{Al}_{\mathrm{o}}$, mesmo a $40 \mathrm{~cm}$ de profundidade (Tabela 5). No extrato de aveia-preta, 
a contribuição do $\mathrm{Al}_{\mathrm{o}}$ para o $\mathrm{Al}_{\mathrm{t}}$ diminuiu com a profundidade, enquanto o $\mathrm{Al}_{\mathrm{m}}$ aumentou no mesmo sentido.

A extração de Ca do solo foi maior na presença do ânion succinato do que do citrato (Fig. 3), comportamento inverso ao observado quanto à retenção no solo na presença destes ânions (Fig. 2). Nos extratos de resíduos vegetais, $\mathrm{Ca}$ e $\mathrm{Mg}$ tiverem comportamento diferenciado. No extrato de aveia-preta, o $\mathrm{Mg}$ foi

TABELA 4. Constantes de equilíbrio da protonação e formação de complexos com Al e Ca para ácido cítrico e succínico ${ }^{1}$.

\begin{tabular}{lccc}
\hline Reação & $\log \mathrm{Ks}_{1}$ & Reação & $\log \mathrm{Ks}_{1}$ \\
\hline H+citrato & 5,8 & $\mathrm{H}+$ succinato & 5,3 \\
Al+citrato & 7,4 & Al+succinato & 3,1 \\
Ca+citrato & 3,2 & $\mathrm{Ca}+$ succinato & 2,0 \\
\hline
\end{tabular}

${ }^{1}$ Kwong \& Huang (1979); Hue et al. (1986). retido pelo solo nas camadas superficiais $(5$ e $10 \mathrm{~cm})$ e extraído nas camadas inferiores (20 e $40 \mathrm{~cm})$, enquanto o $\mathrm{Ca}$ foi extraído na mesma proporção em todo perfil de solo (Fig. 3). No extrato de nabo forrageiro, tanto o $\mathrm{Mg}$ quanto o $\mathrm{Ca}$ foram mantidos em solução nos mesmos níveis observados na solução inicial, mesmo após a percolação pela camada de $40 \mathrm{~cm}$ (Fig. 2). No caso do Mg, diferenças de extração entre as soluções puras podem ter sido limitadas pelo baixo teor do elemento no solo, desde que todas as soluções demonstraram extrações equivalentes (Figs. 2 e 3).

Deve ser chamada a atenção para o fato de que a acidez total das soluções, determinada por titulação com $\mathrm{NaOH}$, deveria ser constituída pelo somatório do $\mathrm{Al}_{\mathrm{m}}$ e da acidez devida aos ácidos orgânicos protonados ( $\mathrm{RCOOH})$ (acidez calculada, Tabela 5). No entanto, nos extratos de nabo forrageiro e aveia-preta, principal-

TABELA 5. Alumínio orgânico $\left(\mathrm{Al}_{\mathrm{o}}\right)$, monomérico $\left(\mathrm{Al}_{\mathrm{m}}\right)$, orgânico titulável $\left(\mathrm{Al}_{\mathrm{ot}}\right)$ e acidez total $\left(\mathrm{RCOOH} \mathrm{Al}_{\mathrm{m}}\right)$ calculada e determinada nas soluções puras e de resíduos vegetais.

\begin{tabular}{|c|c|c|c|c|c|c|}
\hline \multirow[t]{2}{*}{ Solução } & \multirow{2}{*}{$\begin{array}{c}\text { Camadas } \\
(\mathrm{cm})\end{array}$} & \multirow[t]{2}{*}{$\mathrm{Al}_{\mathrm{o}}$} & \multirow[t]{2}{*}{$\mathrm{Al}_{\mathrm{m}}$} & \multirow[t]{2}{*}{$\mathrm{Al}_{\mathrm{ot}}{ }^{1}$} & \multicolumn{2}{|c|}{ Acidez total } \\
\hline & & & & & Calculada $^{2}$ & Determinada \\
\hline \multirow[t]{4}{*}{ Citrato $\mathrm{Ca}$} & $0-5$ & 6,26 & 0,47 & 1,19 & 0,73 & 1,92 \\
\hline & $0-10$ & 8,46 & 0,81 & 0,60 & 0,81 & 1,41 \\
\hline & $0-20$ & 7,34 & 0,33 & 0,58 & 0,33 & 0,91 \\
\hline & $0-40$ & 2,45 & 0,21 & 0,33 & 0,21 & 0,54 \\
\hline \multirow[t]{4}{*}{ Citrato K } & $0-5$ & 6,56 & 1,52 & 0,43 & 2,38 & 2,82 \\
\hline & $0-10$ & 10,28 & 0,98 & 1,07 & 0,98 & 2,06 \\
\hline & $0-20$ & 7,23 & 0,39 & 0,74 & 0,39 & 1,13 \\
\hline & $0-40$ & 3,66 & 0,18 & 0,46 & 0,18 & 0,65 \\
\hline \multirow[t]{4}{*}{ Succinato $\mathrm{Ca}$} & $0-5$ & 0,00 & 0,61 & 0,00 & 3,38 & 3,38 \\
\hline & $0-10$ & 0,00 & 0,83 & 0,00 & 4,04 & 4,04 \\
\hline & $0-20$ & 0,00 & 0,67 & 0,00 & 3,04 & 3,04 \\
\hline & $0-40$ & 0,00 & 0,39 & 0,00 & 1,44 & 1,44 \\
\hline \multirow[t]{4}{*}{ Succinato $\mathrm{K}$} & $0-5$ & 0,10 & 0,14 & 0,10 & 2,82 & 2,92 \\
\hline & $0-10$ & 0,04 & 0,23 & 0,04 & 3,55 & 3,59 \\
\hline & $0-20$ & 0,00 & 0,21 & 0,00 & 3,11 & 3,11 \\
\hline & $0-40$ & 0,00 & 0,08 & 0,00 & 1,01 & 1,01 \\
\hline \multirow[t]{4}{*}{ Aveia-preta } & $0-5$ & 1,99 & 0,69 & 1,58 & 2,85 & 4,43 \\
\hline & $0-10$ & 2,17 & 1,29 & 1,67 & 4,74 & 6,41 \\
\hline & $0-20$ & 1,56 & 1,69 & 1,25 & 5,70 & 6,95 \\
\hline & $0-40$ & 0,02 & 0,78 & 0,02 & 3,42 & 3,44 \\
\hline \multirow[t]{4}{*}{ Nabo forrageiro } & $0-5$ & 4,55 & 0,00 & 3,41 & 2,61 & 6,02 \\
\hline & $0-10$ & 8,21 & 0,00 & 4,97 & 1,57 & 6,53 \\
\hline & $0-20$ & 10,45 & 2,38 & 5,30 & 2,44 & 7,74 \\
\hline & $0-40$ & 5,65 & 1,91 & 2,61 & 1,91 & 4,52 \\
\hline
\end{tabular}

${ }^{1}$ Acidez determinada - acidez calculada.

${ }^{2}$ Somatório do $\mathrm{Al}$ monomérico $\left(\mathrm{Al}_{\mathrm{m}}\right)$ e acidez devida aos grupos orgânicos protonados $(\mathrm{RCOOH})$. 
mente, ocorreu uma grande diferença entre o valor determinado e o valor calculado. Essa diferença pode ser atribuída ao que foi denominado de $\mathrm{Al}$ orgânico titulável $\left(\mathrm{Al}_{\mathrm{ot}}\right)$ (Tabela 5), uma fração do $\mathrm{Al}_{\mathrm{o}}$, na qual os complexos formados com Al seriam estáveis o suficiente para permitir sua passagem pela resina de troca catiônica, mas não para impedir que o mesmo fosse hidrolisado durante a titulação. Mesmo para ligantes fortes como o citrato haveria uma fração do $\mathrm{Al}_{\mathrm{o}}$, que poderia ser hidrolisada (Tabela 5). Tal fato demonstra que os extratos de nabo forrageiro e aveiapreta possuem uma grande diversidade de compostos orgânicos com capacidade de complexação de $\mathrm{Al}$ diferenciada.

$\mathrm{O}$ pH em $\mathrm{CaCl}_{2}$ nas soluções puras aumentou em relação ao controle apenas na camada superficial, sendo o maior efeito observado para a solução de citrato de $\mathrm{Ca}$ (Fig. 4). De modo geral, o pH na camada de 0 a 5 esteve entre o pH inicial do solo, 4,1 e o pH das soluções, 5,0. Nos extratos de resíduos vegetais, o aumento de $\mathrm{pH}$ acima do controle foi observado até na camada de 20 a $40 \mathrm{~cm}$, sendo o de nabo forrageiro mais efetivo do que o de aveia-preta (Fig. 4), apesar de o pH inicial do extrato de aveiapreta ser superior (Tabela 3).

Com a elevação do $\mathrm{pH}$, o teor de $\mathrm{Al}$ trocável diminuiu em todos os tratamentos, e novamente o maior efeito observado foi no citrato de $\mathrm{Ca}$, entre as soluções puras, e no nabo forrageiro, entre os extratos de resíduos vegetais (Fig. 5). Nas soluções puras, o

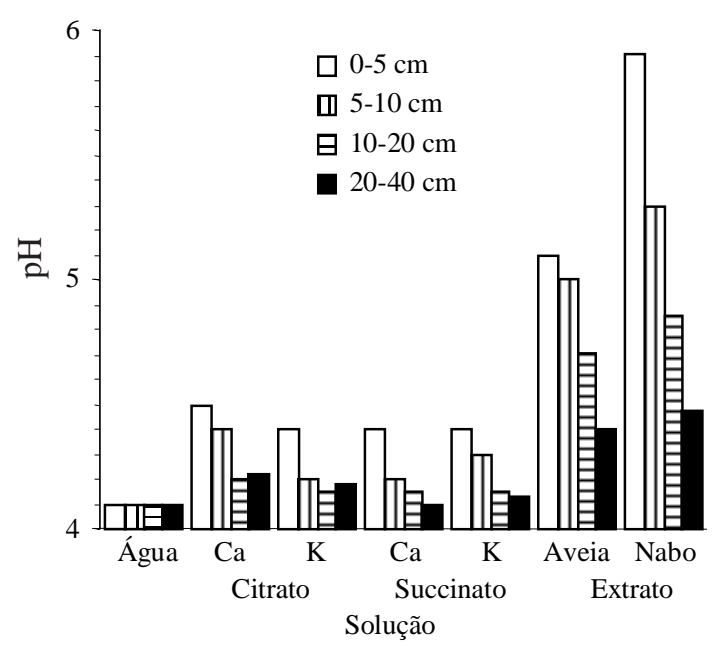

FIG. 4. pH $\left(\mathrm{CaCl}_{2}\right)$ em diferentes camadas do solo após percolação das soluções pela coluna de $40 \mathrm{~cm}$.

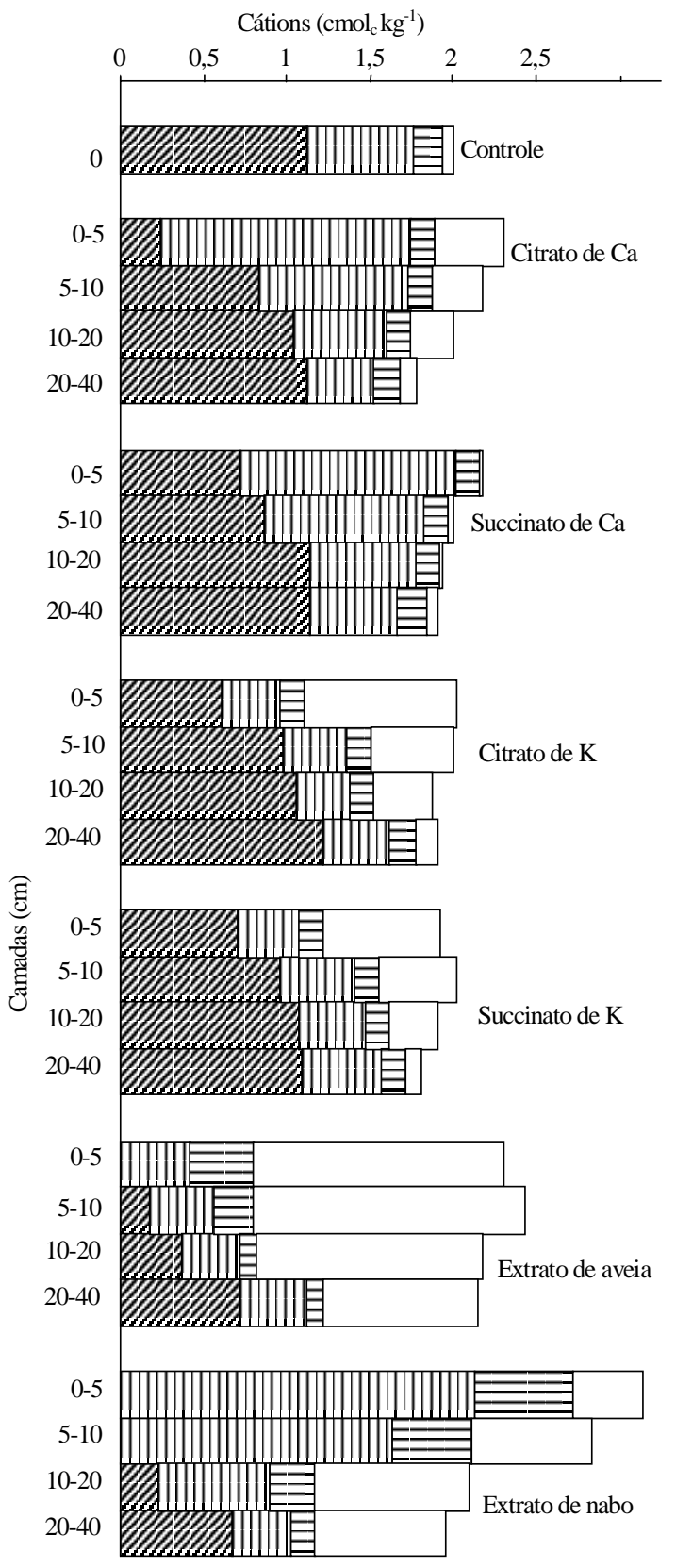

FIG.5. Teores trocáveis de $\mathrm{K} \square, \mathrm{Ca}$ 四, Mg 目 e Al $\mathbb{Z}$, em diferentes camadas $(0-5,5-10,10-20$ e 20-40 cm) da coluna de $40 \mathrm{~cm}$ de profundidade após a percolação das soluções puras de citrato (Ca e K) e succinato (Ca e K) e dos extratos de nabo forrageiro e aveia-preta. A camada zero corresponde ao teor de cátions trocáveis no controle. 
efeito foi observado até, no máximo, $10 \mathrm{~cm}$, enquanto nos extratos de resíduos vegetais atingiu a camada de 20 a $40 \mathrm{~cm}$. Nos extratos de resíduos vegetais ou nas soluções puras contendo citrato, a complexação orgânica também teria um importante papel na diminuição do teor de Al trocável, em face do elevado teor extraído (Figs. 2 e 3 ). A capacidade de troca efetiva $(\mathrm{Ca}+\mathrm{Mg}+\mathrm{K}+\mathrm{Al})$ praticamente não foi alterada nas soluções puras, enquanto nos extratos de resíduos vegetais ocorreu aumento até a camada de $10 \mathrm{~cm}$ (Fig. 5), o que demonstra que apenas os últimos teriam alcalinidade suficiente para a geração de cargas negativas dependentes de $\mathrm{pH}$.

A ocupação do complexo de troca por Ca foi similar em ambas as soluções puras, citrato de $\mathrm{Ca}$ e succinato de Ca (Fig. 5), apesar de o succinato apresentar maior capacidade de manter Ca em solução do que o citrato (Fig. 2). Por outro lado, o teor de $\mathrm{Ca}$ trocável diminuiu quando o cátion estava ausente na solução aplicada (citrato de K, succinato de K) ou em baixa proporção relativa, no caso do extrato de aveia-preta (Fig. 5). O extrato de nabo forrageiro proporcionou o maior aumento no teor trocável de Ca entre os tratamentos avaliados, mesmo na camada de 10 a $20 \mathrm{~cm}$ (Fig. 5). Devido ao teor elevado do elemento no referido extrato (Tabela 3 ), a retenção de Ca pelo complexo de troca teve pouco reflexo no seu teor em solução até $20 \mathrm{~cm}$ de profundidade (Fig. 2). Na camada de 20 a 40 cm, a extração de Ca do solo, indicada pela redução do teor trocável, manteve o teor em solução no mesmo nível das camadas anteriores (Fig. 2). O Mg foi extraído do solo em todas as soluções puras, razão pela qual seu teor trocável foi reduzido. Nos extratos de resíduos vegetais, o $\mathrm{Mg}$ foi retido nas camadas superficiais, sendo extraído a partir de $10 \mathrm{~cm}$ no de aveia-preta e a partir de $20 \mathrm{~cm}$ no de nabo forrageiro (Fig. 5).

$\mathrm{O} \mathrm{K}$ foi indiscriminadamente o cátion mais retido pelo solo quando presente em solução (Figs. 2 e 3); deste modo, seu teor trocável aumentou, principalmente na camada superficial (Fig. 5). No extrato de nabo forrageiro, em face do elevado teor de $\mathrm{Ca}$ (Tabela 3), a retenção de $\mathrm{K}$ foi menor do que a de $\mathrm{Ca}$ na camada superficial, sendo, sua participação, relativa no complexo de troca aumentada em profundidade, à medida que a de Ca era diminuída (Fig. 5).
A mobilidade de íons foi influenciada principalmente pela constante de estabilidade dos complexos orgânicos formados e sua interação com a superfície de troca. A maior retenção de $\mathrm{H}$ e Ca pelo solo na presença do ânion citrato em relação ao succinato pode ser entendida pela constante de estabilidade dessas formas orgânicas em relação ao Al (Tabela 4). As formas ácida e de citrato de $\mathrm{Ca}$ possuem constante de estabilidade inferior à forma citrato de $\mathrm{Al}$; desse modo, tanto $\mathrm{H}$ quanto $\mathrm{Ca}$ seriam substituídos pelo Al do solo no complexo orgânico. Conseqüentemente, o Ca ocuparia a carga liberada no complexo de troca pela complexação do Al, aumentando o seu teor trocável nas camadas superiores. $\mathrm{O} \mathrm{Al}$, por sua vez, teria seu teor trocável reduzido pela formação de complexos orgânicos solúveis e posterior mobilização pelo fluxo de água.

Esses são resultados comumente observados em estudos utilizando citrato ou fulvato de $\mathrm{Ca}$, embora o fulvato tenha sido menos efetivo na extração do $\mathrm{Al}$ e, conseqüentemente, na retenção do Ca (Watt et al., 1991; Noble et al., 1995; Smith et al., 1995; Liu \& Hue, 1996). No caso do succinato, a estabilidade da forma ácida é superior à observada quanto às formas succinato de Al e succinato de Ca (Tabela 4), o que explica a manutenção de $\mathrm{H}$ em solução. A extração preferencial de $\mathrm{Ca}$ em relação a $\mathrm{Al}$, no entanto, pode ser explicada pela maior energia de ligação do Al em relação ao Ca nas cargas de superfície nos colóides do solo. Tal comportamento justifica a maior efetividade de succinato na extração de Ca em relação a citrato, que é mais efetivo na extração de $\mathrm{Al}$.

A lixiviação preferencial de $\mathrm{Ca}$ em relação a $\mathrm{K}$, nas soluções puras e nos extratos de resíduos vegetais, é outro indicativo da formação de complexos orgânicos com Ca, uma vez que em sistemas inorgânicos a seletividade do complexo de troca é maior para o $\mathrm{Ca}$ (Loyola Junior \& Pavan, 1989). Na forma complexada, o Ca teria sua carga líquida alterada pela formação de complexos orgânicos de carga nula ou até negativa. Diante da carga líquida negativa do solo, esses complexos seriam preferencialmente lixiviados em relação ao K. Esse comportamento poderia explicar, por exemplo, a grande retenção do K e a lixiviação do Ca no solo, no caso do extrato de aveia-preta.

A química do $\mathrm{Al}$ em solução também pode estar envolvida na extração de Ca pelos extratos de nabo 
forrageiro e aveia-preta. Após a percolação através das camadas de solo, os extratos apresentaram teores consideráveis de $\mathrm{Al}$ na forma orgânica passíveis de hidrólise, indicando a presença de complexos de menor estabilidade ( $\mathrm{Al}_{\mathrm{ot}}$, Tabela 5). A hidrólise desses complexos contribuiria para a redução do Al em solução e extração de $\mathrm{Ca}$ segundo a seqüência de reações:

$$
\begin{aligned}
& \mathrm{RCOO}^{-} 1 / 3 \mathrm{Al}^{3+} \Leftrightarrow \mathrm{RCOO}^{-}+1 / 3 \mathrm{Al}^{3+} \\
& \mathrm{SOLO}^{-} 1 / 2 \mathrm{Ca}^{2+}+1 / 3 \mathrm{Al}^{3+} \Leftrightarrow \mathrm{SOLO}^{-} 1 / 3 \mathrm{Al}^{3+}+1 / 2 \mathrm{Ca}^{2+}(2) \\
& \mathrm{RCOO}^{-}+1 / 2 \mathrm{Ca}^{2+} \Leftrightarrow \mathrm{RCOO}^{-} 1 / 2 \mathrm{Ca}^{2+} \\
& \mathrm{RCOO}^{-} 1 / 3 \mathrm{Al}^{3+}+\mathrm{SOLO}^{-} 1 / 2 \mathrm{Ca}^{2+} \Leftrightarrow \mathrm{SOLO}^{-1} 1 / 3 \mathrm{Al}^{3+}+ \\
& \mathrm{RCOO}^{-} 1 / 2 \mathrm{Ca}^{2+}
\end{aligned}
$$

Com a percolação dos extratos através das camadas de solo, haveria a formação dos complexos orgânicos com Al até a saturação da capacidade de complexação do extrato. Os complexos de menor estabilidade seriam passíveis de hidrólise, liberando o Al complexado em solução (equação 1). O Ca seria trocado por $\mathrm{Al}$ no complexo de troca, dada a maior afinidade pelo último (equação 2), e pela complexação com o ânion orgânico, antes complexado com o $\mathrm{Al}$, o Ca passaria a solução, sendo então mobilizado (equação 3). A equação 4 representa o saldo das reações.

Tais observações permitem o entendimento dos processos que ocorreram nas soluções de resíduos vegetais. No caso do extrato de aveia-preta, os ácidos orgânicos presentes em solução estariam na forma de sais, principalmente de K. Formas protonadas não seriam observadas, dada a ausência de H titulável (Tabela 3). Nessa condição, seria de se esperar que diferentes complexos orgânicos fossem formados durante a percolação do extrato através do solo. De fato, observou-se que $\mathrm{H}, \mathrm{Ca}$ e $\mathrm{Al}$ tiveram seu teor em solução aumentado à medida que o de $\mathrm{K}$ foi sendo diminuído com a profundidade. Desde que o íon K não pode responder por esse processo, devido à baixa seletividade do complexo de troca, a extração de $\mathrm{Ca} \mathrm{e} \mathrm{H}$ pode ser atribuída à formação de complexos com ácidos orgânicos do tipo succínico e a de $\mathrm{Al}$ com os do tipo cítrico.
No caso do extrato de nabo forrageiro, embora a presença de ácidos orgânicos na forma de sais de $\mathrm{K}$ também fosse a mais importante, também ocorreriam sais na forma de $\mathrm{Ca}$ e $\mathrm{Mg}$ (Tabela 3). Nessas condições, os ácidos orgânicos associados a $\mathrm{Ca}$ e $\mathrm{Mg}$ no extrato inicial teriam grande contribuição para a manutenção tanto do $\mathrm{Ca}$ quanto do $\mathrm{Mg}$ em solução, principalmente durante a percolação através das camadas superficiais de solo. Desse modo, tais compostos teriam o mesmo comportamento observado para o ácido succínico. Por outro lado, a diminuição do teor de $\mathrm{H}$ e o aumento do de Al em solução com a percolação do extrato se assemelha ao comportamento observado quanto ao ácido cítrico. Considerando a maior proporção de cátions lixiviados pelo extrato de nabo forrageiro em relação ao de aveia-preta, supõese que o primeiro apresentaria maior quantidade e diversidade de ácidos orgânicos em relação ao segundo.

Vários trabalhos têm indicado os ácidos fúlvicos como compostos orgânicos com alta capacidade para detoxificação do Al e mobilização de $\mathrm{Ca}$ para a subsuperfície do solo (Watt et al., 1991; Noble et al., 1995; Smith et al., 1995; Liu \& Hue, 1996). Os resultados observados neste trabalho indicam que compostos orgânicos hidrossóluveis de baixo peso molecular, extraídos de resíduos vegetais de adubos verdes coletados no estádio de pleno florescimento, também apresentam o mesmo comportamento. Desse modo, o resíduo de aveia-preta, quando manejado em solos que receberam calagem, teria potencial para transporte de Ca para a subsuperfície, conforme já observado por Pavan (1994). Já o resíduo de nabo forrageiro teria a vantagem de associar a capacidade de mobilização de Ca com a de imobilização do Al. Considerando, ainda, o alto teor de $\mathrm{Ca}$ no resíduo de nabo forrageiro, o uso de ambos em sistemas de rotações de culturas permitiria a reciclagem do elemento, reduzindo os riscos de perdas por lixiviação fora do alcance do sistema radicular.

\section{CONCLUSÕES}

1. Os resíduos vegetais de nabo forrageiro e aveiapreta apresentam compostos orgânicos hidrossolúveis capazes de formar complexos estáveis com $\mathrm{Al} \mathrm{e} \mathrm{Ca}$.

Pesq. agropec. bras., Brasília, v.34, n.12, p.2267-2276, dez. 1999 
2. Na forma complexada, a mobilidade do Al e do Ca em solo ácido com cargas variáveis dependentes de $\mathrm{pH}$ é aumentada.

\section{REFERÊNCIAS}

AOYAMA, M. Fractionation of water-soluble organic substances formed during plant residue decomposition and high performance size exclusion chromatography of the fractions. Soil Science and Plant Nutrition, Tokio, v.42, n.1, p.21-30, 1996a.

AOYAMA, M. Use of high performance size exlcusion chromatography to monitor the dynamics of water soluble organic substances during the decomposition of plant residues in soil. Soil Science and Plant Nutrition, Tokio, v.42, n.1, p.31-40, 1996 b.

BESSHO, T.; BELL, L.C. Soil solid and solution phase changes and mung bean response during amelioration of aluminum toxicity with organic matter. Plant and Soil, Dordrecht, v.140, n.2, p.183-196, 1992.

CAMPBELL, P.G.C.; BISSON, M.; BOUGIE, M.B.R.; TESSIER, A.; VILLENEUVE, J.P. Speciation of aluminum in acidic freshwaters. Analitycal Chemistry, Washington, v.55, n.14, p.2246-2252, 1983.

DRISCOLL, C.T. A procedure for the fractionation of aqueous aluminum in dilute acidic waters. International Journal of Environmental Analytical Chemistry, New York, v.16, p.267-283, 1984.

HUE, N.V.; AMIEN, I. Aluminum detoxification with green manures. Communications in Soil Science and Plant Analysis, New York, v.20, n.15/16, p.14991511, 1989.

HUE, N.V.; CRADDOCK, G.R.; ADAMS, F. Effect of organic acids on aluminum toxicity in subsoils. Soil Science Society of America. Journal, Madison, v.50, n.1, p.28-34, 1986.

KWONG, N.K.K.; HUANG, P.M. The relative influence of low-molecular-weight, complexing organic acids on the hydrolisis and precipitation of aluminum. Soil Science, Oxford, v.128, n.6, p.337-342, 1979.

LEAL, A.C.; PAVAN, M.A.; CHAVES, J.C.D.; INOUE, M.T.; KOHELER, C.W. Effect of leucaena residues on soil acidity. Forest, Farm, and Community Tree Research Reports, Morrilton, v.1, p.97-102, 1996.
LIU, J.; HUE, N.V. Ameliorating subsoil acidity by surface application of calcium fulvates derived from common organic materials. Biology and Fertility of Soils, Berlim, v.21, p.264-270, 1996.

LOYOLA JUNIOR, E.; PAVAN, M.A. Seletividade de troca de cátions em solos ácidos. Revista Brasileira de Ciência do Solo, Campinas, v.13, n.2, p.131138, 1989.

MIYAZAWA, M.; PAVAN, M.A.; CALEGARI, A. Efeito do material vegetal na acidez do solo. Revista Brasileira de Ciência do Solo, Campinas, v.17, n.3, p.411-416, 1993.

NOBLE, A.D.; RANDALL, P.J.; JAMES, T.R. Evaluation of two coal-derived organic products in ameliorating surface and subsurface soil acidity. European Journal of Soil Science, Oxford, v.46, n.1, p.6575,1995 .

OLIVEIRA, E.L.; PAVAN, M.A. Control of soil acidity in no-tillage system for soybean production. Soil and Tillage Research, Amsterdam, v.38, p.47-57, 1996.

PAVAN, M.A. Movimentação de calcário no solo através de técnicas de manejo da cobertura vegetal em pomares de macieira. Revista Brasileira de Fruticultura, Cruz das Almas, v.16, n.1, p.86-91, 1994.

POHLMAN, A.A.; McCOLL, J.G. Kinetics of metal dissolution from forest soils by soluble organic acids. Journal of Environmental Quality, Madison, v.15, n.1, p.86-92, 1986.

SANCHEZ, P.A.; BANDY, D.E.; VILLACHICA, J.H.; NICHOLAIDES, J.J. Amazon basin soils: management for continuous crop production. Science, Washington, v.216, p.821-827, 1982.

SMITH, C.J.; GOH, K.M.; BOND, W.J.; FRENEY, J.R. Effects of organic and inorganic calcium compounds on soil-solution $\mathrm{pH}$ and $\mathrm{Al}$ concentration. European Journal of Soil Science, Oxford, v.46, n.1, p.5363, 1995.

WATT, H.H. van der; BARNARD, R.O.; CRONJE, I.J.; DEKKER, J.; CROFT, G.J.B.; WALT, M.M. van der. Amelioration of subsoil acidity by application of a coal-derived calcium fulvate to the soil surface. Nature, Londres, v.350, p.146-148, 1991.

WRIGHT, R.J.; HERN, J.L.; BALIGAR, V.C.; BENNETT, O.L. The effect of surface applied soil amendments on barley root growth in an acid subsoil. Communications in Soil Science and Plant Analysis, New York, v.16, n.2, p.179-192, 1985. 